\title{
LORENZ OBERLINNER
}

\section{Die „Epiphaneia“ des Heilswillens Gottes in Christus Jesus}

Zur Grundstruktur der Christologie der Pastoralbriefe 


\section{Die »Epiphaneia« des Heilswillens Gottes in Christus Jesus Zur Grundstruktur der Christologie der Pastoralbriefe* \\ von Lorenz Oberlinner \\ (Hauptstr 24, 7801 Buchenbach)}

\section{Die Problemstellung}

1. Wenn P. Trummer von der Christologie als einem der »eigenartigsten Phänomene der Past « spricht ${ }^{1}$, dann dürfen wir dies als Beleg dafür werten, daß der hier erhobene Anspruch, die Grundstruktur einer »Christologie der Past « herauszuarbeiten, als keineswegs unbestrittenes Unterfangen verstanden werden kann ${ }^{2}$. Mit der Feststellung E. Lohses, die Past entwickelten »keine eigenen christologischen Aussagen, sondern übernehmen ausschließlich formelhafte Wendungen « ${ }^{3}$, »an keiner Stelle « finde sich »eine Aussage über das Werk Christi, die der Verfasser selbst formuliert hätte ${ }^{4}$, wird uns offensichtlich eine recht enge Grenze gezogen. Ist zwar damit noch nicht die Berechtigung der Rückfrage nach der Christologie der Past bestritten und ebensowenig, daß zentrale christologische Aussagen sie prägen und bestimmen, so sind wir dann doch eher auf die Frage nach der Christologie des traditionellen, d.h. alten Formelgutes, ihrer Herkunft und Eigenart verwiesen, denn auf die Frage nach der Christologie der Past. Wenn tatsächlich »das eigentlich Bezeichnende der Christologie der Pastoralbriefe ... ihr altertümlicher Cha-

* Der vorliegende Aufsatz ist die leicht überarbeitete und durch Anmerkungen ergänzte Fassung des Vortrages, der im Rahmen des Habilitationsverfahrens am 19.7.79 vor der Theol. Fakultät der Universität Freiburg/Br. gehalten wurde.

1 P. Trummer, Die Paulustradition der Pastoralbriefe, BET 8, Frankfurt/M. 1978, 193.

2 Vgl. etwa W. Stenger, Der Christushymnus 1 Tim 3 16. Eine strukturanalytische Untersuchung, RStTh 6, Frankfurt/Bern 1977, 257-259, der seine Reserve gegenüber einer »Christologie« der Past u.a. schon dadurch bekundet, daß er sie in Anführungszeichen setzt.

3 E. Lohse, Die Entstehung des Neuen Testaments, ThW 4, Stuttgart 1972, $63 \mathrm{f}$.

4 E. Lohse, Grundriß der neutestamentlichen Theologie, ThW 5, Stuttgart 1974, 149. Vgl. auch S. Schulz, Die Mitte der Schrift. Der Frühkatholizismus im Neuen Testament als Herausforderung an den Protestantismus, Stuttgart/Berlin 1976, 105: „In der Christologie wird nichts Eigenes geboten, sondern beherrschen übernommene Formeln das Feld.« 
rakter « ist ${ }^{5}$, dann wird es schwer, wenn nicht gar unmöglich sein, über eine Zusammenstellung des traditionellen Gutes und die Feststellung der jeweiligen christologischen Aussage hinauszukommen, da von vornherein anzunehmen ist, daß »die verwendeten kerygmatischen Formeln und Traditionen sich gegen einen systematisierenden Vergleich wehren ${ }^{6}{ }^{6}$.

Nun ist gleich vorneweg die Frage zu stellen, ob man von der Beobachtung aus, daß der Verf. der »Briefe « häufig auf überliefertes Glaubensgut und formelhafte Wendungen zurückgreift, gleich darauf schließen darf, daß diese dann auch als das Charakteristikum der Christologie der Past anzusehen sind; es ist zumindest nicht a priori auszuschließen, daß der »Rahmen «, in den diese Traditionen eingefügt und aufgenommen wurden, eine neue und eigenständige christologische Konzeption abgibt, welcher dieses traditionelle Glaubens-, Bekenntnis- und Liedgut untergeordnet wird.

2. Das angedeutete Problem der Bestimmung der Christologie würde auch für den Fall sich stellen, daß man gegen die heute weit überwiegende Erklärung dieser »Briefe « als vom historischen Pls unabhängiges Werk sie entweder ganz Pls zuschreiben ${ }^{7}$ oder aber doch im Grundsätzlichen und Wesentlichen auf den Apostel selbst zurückführen wollte, sei es in der Form der Sekretärshypothese ${ }^{8}$, der Fragmentenhypothese ${ }^{9}$, oder aber auch in der von P. Dornier formulierten Variante, ein PlsSchüler habe in Rom in den Jahren 70-80 die drei Briefe des Apostels

5 N. Brox, Die Pastoralbriefe, RNT 7, Regensburg 1969, 163.

6 So in der Zusammenfassung zur Christologie der Past bei P. Trummer, Paulustradition (s. Anm. 1), 207 (vgl. 193-208), der diese Zusammenfassung einleitet: »Die Christologie der Past zeigt insgesamt eine eigentümliche Mischung aus $\mathrm{P}$ (aulus), traditionellem - auch nichtpln - Gut und eigener Terminologie ... . Vgl. auch A. T. Hanson, Studies in the Pastoral Epistles, London 1968, 110-113.

7 In jüngerer Zeit etwa C. Spicq, Les Épîtres Pastorales, Paris ${ }^{4} 1969$, bes. 157-214; B. Reicke, Chronologie der Pastoralbriefe, in: ThLZ 101, 1976, 81-94, bes. 84-92.

8 Vgl. J. N. D. Kelly, A Commentary on the Pastoral Epistles, London 1963, 21-27. 30-34; G. Holtz, Die Pastoralbriefe, ThHK 13, Berlin 1965, 13-16; J. Jeremias, Die Briefe an Timótheus und Titus, NTD 9, Göttingen 1975, 9 f.; W. Metzger, Die letzte Reise des Apostels Paulus. Beobachtungen und Erwagungen zu seinem Itinerar nach den Pastoralbriefen, AzTh 59, Stuttgart 1976, 8-16; ders., Der Christushymnus 1. Timotheus 3, 16. Fragment einer Homologie der paulinischen Gemeinden, AzTh 62, Stuttgart 1979, 11. 147. 163, Anm. 357.

9 Als solche Fragmente echter Pls-Briefe, die der Verf. der Past in seine »Briefe « eingearbeitet habe, werden jedoch ausschließlich die persönlichen Notizen v. a. des 2 Tim in Anspruch genommen; s. E. F. Scott, The Pastoral Epistles, London 1948 (= 1936), XVIII. XXII (vgl. XVf.); W. Barclay, Briefe an Timotheus. Brief an Titus. Brief an Philemon (dt. v. E. Leseberg), Wuppertal 1974, $18 \mathrm{f}$. (vgl. $10 \mathrm{ff}$ ); C. K. Barrett, The Pastoral Epistles, Oxford 1963, 10-12 (vgl. 18f.); A. T. Hanson, Studies (s. Anm. 6), 3; auch G. Holtz, Past (s. Anm. 8), 16 f. 
entsprechend den Bedürfnissen der Kirche seiner Zeit überarbeitet ${ }^{10}$; denn die nicht wegzudiskutierenden Unterschiede gegenüber den unbestrittenen Paulinen v.a. in der Christologie bedürfen auch dann noch einer Erklärung ${ }^{11}$. Obwohl die Christologie neben anderen Faktoren ein wichtiges Kriterium gerade für die Beurteilung der Verfasserfrage abgibt, nehmen wir als Ausgangspunkt für unsere Fragestellung die meistvertretene und wohl auch bestbegründete Hypothese, daß die Past weder von Pls selbst abgefaßt noch auch in irgendeiner Weise initiiert worden sind, sondern von einem unbekannten Christen (möglicherweise einem kirchlichen Amtsträger) um die Jahrhundertwende geschrieben worden sind $^{12}$.

Mit diesem Urteil zur Verfasserfrage ist jedoch die Berücksichtigung der unbestritten echten Paulinen für die Christologie der Past eingeschlossen. Zum einen muß man von der Voraussetzung ausgehen, daß der Verf. (die) echte(n) Pls-Briefe, wenn nicht gar schon ein Corpus Paulinum gekannt hat ${ }^{13}$; zum anderen impliziert die Tatsache, daß unser Autor unter dem Namen und damit der Autorität des Apostels schreibt,

10 P. Dornier, Les Épîtres Pastorales, Paris 1969, $24 \mathrm{f}$.

$\mathrm{Zu}$ den einzelnen Hypothesen und ihren Problemen s. P. Trummer, Paulustradition (s. Anm. 1), 19-56.

11 Wenn B. Reicke, Chronologie (s. Anm. 7), fragt, ob es »lieber einem Vertreter der späteren kirchlichen Orthodoxie und Hierarchie zuzumuten (ware), einige von Paulus stammende Fragmente und Gedanken auszugraben oder konstruiert zu haben, um das Programm des sog. Frühkatholizismus unter dem Namen des Paulus zu verbreiten, und zwar ohne die alteren, damals allgemein bekannten Briefe des Paulus als konsequentes Vorbild fur Terminologie und Phraseologie zu verwenden» (82), oder wenn er es als "primitiven Anachronísmus « bezeichnet, »zu behaupten, jemand hätte dreißig, fünfzig oder neunzig Jahre nach dem Tod des Paulus sich die Mühe gegeben, aus der Apostelgeschichte und den Paulusbriefen einige Namen und Daten herauszupicken, um die Zeitgenossen mit gefalschten Paulusbriefen an Privatpersonen zu beglücken, ohne sich über derartige Antiquitäten hinaus um eine uberzeugende Imitation der paulinischen Ausdrucksweise und Begriffswelt zu kümmern « (83), dann wird damit doch auch eine gegenüber den allgemein als echt anerkannten Pls-Briefen erkennbare und unbestreitbare Besonderheit der Past zugestanden, welche folglich nicht nur für den Fall der Annahme eines pseudepigraphen Verf. einer Erklärung bedarf. Ist es Zufall, daß Reicke bei der Nennung (und Zurückweisung) von Gegenargumenten zur pln Verfasserschaft (92-94) auf die zentralen christologischen Unterschiede nicht eingeht?

12 N. Brox, Past (s. Anm. 5), 57f. (22-60). Vgl. dazu auch W. G. Kümmel, Einleitung in das Neue Testament, Heidelberg 191978, 326-339; J. Schmid, Einleitung in das Neue Testament, Freiburg 1973, 515-537; E. Lohse, Entstehung (s. Anm. 3), 61-65.

13 Vgl. N. Brox, Past (s. Anm. 5), 67f.; P. Trummer, Paulustradition (s. Anm. 1), bes. 88f. 107. 241-243. "Mit Sicherheit « hat der Verf. nach A. Lindemann »den paulinischen Röm« gekannt, »und aller Wahrscheinlichkeit nach 1 Kor«: Paulus im ältesten Christentum. Das Bild des Paulus und die Rezeption der paulinischen Theologie in der frühchristlichen Literatur bis Marcion, BHTh 58, Tübingen 1979, 146 (134-149). 
einen hohen Anspruch und macht auch für die Christologie die »Frage nach der Identität oder Differenz gegenüber Paulus « unumgänglich ${ }^{14}$. Letztere Frage kann jedoch nicht unter dem präjudizierenden Gesichtspunkt eines damit zu fällenden Urteils über die »Sachgemäßheit dieser Theologie « stehen ${ }^{15}$. So sehr die Tatsache, daß der Verf. seine »Briefe « als »Wort des Paulus « ausgibt ${ }^{16}$, dazu berechtigt, die beiderseitigen theologischen und christologischen Aussagen einander gegenüberzustellen und nach der Identität bzw. Differenz zu fragen, so wenig sinnvoll ist es doch, dies unter dem übergeordneten Aspekt einer Wertung zu tun. Schon der Umstand, daß ein Christ der 2. oder 3. christlichen Generation »Pls «-Briefe schreibt, ist nur so zu verstehen, daß es gar nicht um eine Nachahmung oder Wiederholung auch der pln Christologie gehen konnte. Es ist deshalb von vornherein nicht nur eine Pls-Interpretation, sondern auch eine nur selektive Verwendung der pln Tradition zu erwarten.

3. Somit hat der Versuch einer Bestimmung der Christologie der Past schon in seinem Ansatz die Verknüpfung und das Zusammenwirken von drei Größen als konstitutive Faktoren in Rechnung zu stellen: Einmal die für diese Schreiben charakteristische Übernahme neuer Begriffe und Vorstellungen aus der hellenistischen Umwelt; sodann die Aufnahme geprägter Traditionen und Formeln, die z.T. älteste christologische Aussagen enthalten; und schließlich die Verwendung pln Gutes, das vom Verf. übernommen und in seinem Sinn interpretiert worden ist. In der vorgestellten Reihenfolge ist zugleich das Programm für unsere Analyse mitgegeben: Es geht um die Frage, ob und auf welche Weise Einzeltraditionen aus den Pls-Briefen und vor- und außerpln Úberlieferungsstücke in eine neue, einheitliche und umfassende christologische Konzeption gebracht worden sind, die geprägt ist durch die neue Begrifflichkeit. Dieses Vorgehen ist zu rechtfertigen aus der mit der Tatsache der Abfassung der »Briefe« belegten Erkenntnis, da $\beta$ der Verf. Bisheriges ergänzen oder präzisieren, aber auch Neues sagen und damit Wegweisungen für die Zukunft geben wollte.

In einem ersten Abschnitt geht es uns deshalb um das Wort $\dot{\varepsilon} \pi \iota-$

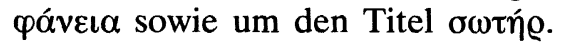

Für das traditionelle Formelgut stehen die für die Christologie der Frühzeit zentralen Aussagen von der Heilsmittlerschaft des Todes Jesu in 1 Tim 2 (5.) 6 und Tit 214 , zusammen mit 1 Tim 115 (vgl. auch den

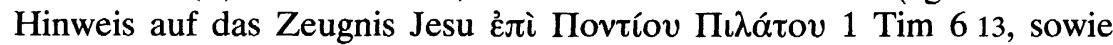
den Hymnus 1 Tim 3 16).

\footnotetext{
14 Vgl. S. Schulz, Mitte (s. Anm. 4), 109.

15 Gegen S. Schulz, Mitte (s. Anm. 4), 109 (vgl. 108: „Das Niveau des Paulus ist nirgends erreicht «). Vgl. dazu auch die Kritik bei A. Lindemann, Paulus (s. Anm. 13), 142.

16 Vgl. S. Schulz, Mitte (s. Anm. 4), 109.
} 
In bezug auf die Úbernahme christologischer Aussagen aus der pln Tradition stehen stellvertretend 2 Tim 28 (vgl. Röm 13f.) sowie die

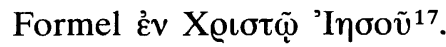

\section{Christologische Zentralaussagen und ihre Verknüpfung in den Past}

\section{Die neue Begrifflichkeit}

Als auffällig und bedeutsam muß das gegenüber dem übrigen NT, sieht man von 2 Petr ab (2 Petr 11.1122032 .18 ), häufige Vorkommen von $\sigma \omega \tau$ tr $\varrho$ in den Past gewertet werden ${ }^{18}$. Zunächst jedoch überrascht die Beobachtung, daß von den 10 Belegen $\sigma \omega \tau \eta \dot{\varrho}$ in 6 Fällen auf Gott bezogen ist ( 1 Tim 11123410 Tit 13221034 ). Dadurch wird schon

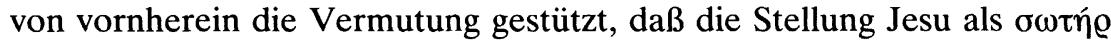
wesentlich geknüpft ist an das gleichlautende Gottesprädikat und nur gedeutet werden kann in Verbindung mit diesem.

Der Verf. der Past läßt Pls seinen Apostolat an den »Auftrag Gottes, unseres Retters « binden (1 Tim 1 1). Das »Kerygma «, als dessen Verkünder der fiktiv schreibende Pls sich vorstellt, ist Vermittlung des in Gott und seinem Ratschluß gründenden Heils (Tit 13). Daß dieses Heil nicht partikularistisch und exklusiv verstanden ist, macht die Erläuterung zu 1 Tim 23 deutlich, daß nämlich »alle Menschen « nach dem Willen »Gottes, unseres Heilandes " gerettet werden und zur »Erkenntnis der Wahrheit « kommen sollen (vgl. v. 4). Gott wird als »Retter aller Menschen, besonders derer, die gläubig sind «, vorgestellt (1 Tim 4 10);

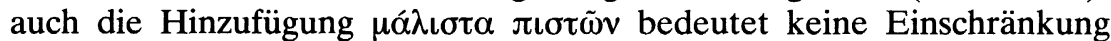
des umfassenden Heilswillens ${ }^{19}$, sondern eine Präzisierung hinsichtlich

17 Die pln Rechtfertigungslehre ist bewußt ausgespart, da für deren Behandlung eine ausführlichere Auseinandersetzung notwendig wäre; dazu aus jüngerer Zeit U. Luz, Rechtfertigung bei den Paulusschülern, in: J. Friedrich u. a. (Hrsg.), Rechtfertigung. FS E. Käsemann, Tübingen/Göttingen 1976, 365-383, bes. 378-382; P. Trummer, Paulustradition (s. Anm. 1), 173-193. Während bei Trummer der Satz als bezeichnend gelten kann, daß »neben der geschichtlich bedingten Änderung und Entschärfung des pln Ansatzes sich in den Past aber auch deutliche Tendenzen zu einer Ausweitung und Radikalisierung der pln Thesen (zeigen)« (a.a.O. 193), erscheint bei Luz die im einleitenden Abschnitt stehende Aussage charakteristisch, die Rechtfertigungslehre begegne auch in den Past »in verhältnismäßig peripherer Weise «, wobei er mit der Behauptung, auch für die Past gelte wohl »das Urteil, daß pln Theologie nicht ganz verstanden wurde«, die Erklärung favorisiert, die Rechtfertigungslehre stelle »zu hohe intellektuelle Anforderungen« (a.a.O., 366f., mit Anm. 9).

18 Außer Lk 147 (Hab 3 18; vgl. 1 Sam 2 1) 211 und Act 5311323 nur noch Joh 442 Eph 523 Phil 3201 Joh 414 Jud 25.

19 Vgl. W. Foerster, ThWNT VII, 1018. 
der konkreten Verwirklichung und Vermittlung. Die Verknüpfung der »Rettergott-Aussagen « mit der Gemeindeleiterparänese (so bes. 1 Tim 410 Tit 21034$)^{20}$ bindet diese Vermittlung des Heils für den Menschen an die im Auftrag dieses Gottes mit der Weitergabe des »Glaubensgutes ${ }^{21}$ Verantwortlichen. Es wird ebenfalls nicht zufällig sein, daß die

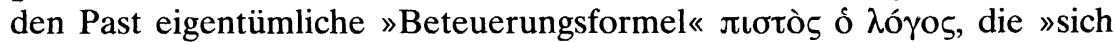
stets im Zusammenhang von Aussagen über das Heil (bzw. den Glauben) findet «22, in 1 Tim 49 und Tit 38 (s. außerdem 1 Tim 11531 2 Tim 2 11) im unmittelbaren Kontext mit den Rettergott-Aussagen steht.

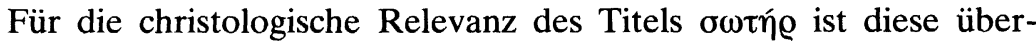
wiegende Verwendung als Gottesprädikat von nicht zu unterschätzender Bedeutung. In Verbindung mit dem das atl Gottesbild grundsätzlich prägenden und bestimmenden Wissen um den das Volk als ganzes wie auch den einzelnen tragenden Heilswillen Jahwes ${ }^{23}$ kann hier der Verf. der Past auf die durch die LXX eingeführte Gottesbezeichnung $\sigma \omega \tau \eta \varrho^{24} \mathrm{zu}$ rückgreifen ${ }^{25}$. Dieser Bezug wird sich dann auch für die Übertragung dieses Titels auf Christus Jesus nicht ganz ausschließen lassen, wenn auch bereits die Tatsache, daß eine innerjüdische Bezeichnung des Messias als $\sigma \omega \tau \eta \dot{\varrho} \varrho$ nicht nachweisbar ist ${ }^{26}$, ein weiteres Bezugsfeld nahelegt. $\mathrm{Zu}$ -

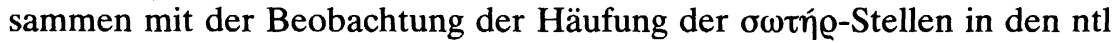
Spätschriften (bes. 2 Petr, dort mit ausschließlichem Bezug auf Jesus) und dem Befund, daß auch sonst in die Past spezifisch hellenistisch ge-

20 Vgl. V. Hasler, Epiphanie und Christologie in den Pastoralbriefen, in: ThZ 33, 1977, 193-209, hier 201.

${ }^{21} \mathrm{Zu} \pi \alpha \varrho \alpha \theta \dot{\kappa} \kappa \eta$ als zentralem Begriff in den Past (1 Tim 6202 Tim 1 12.14) u. a. N. Brox, Past (s. Anm. 5), 235f.; K. Wegenast, Das Verständnis der Tradition bei Paulus und in den Deuteropaulinen, WMANT 8, Neukirchen 1962, 132-144; J. Wanke, Der verkündigte Paulus der Pastoralbriefe, in: W. Ernst u.a. (Hrsg.), Dienst der Vermittlung. FS zum 25-jährigen Bestehen des Phil.-Theol. Studiums im Priesterseminar Erfurt, Leipzig 1977, 165-189, hier 170f.; P. Trummer, Paulustradition (s. Anm. 1), 219222.

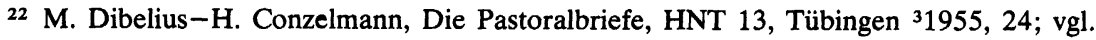
N. Brox, Past (s. Anm. 5), 112-114.

${ }^{23} \mathrm{Vgl}$. A. Deissler, Die Grundbotschaft des Alten Testaments. Ein theologischer Durchblick, Freiburg ${ }^{5} 1978,82$ f., der (im Zusammenhang mit dem Dekalog) vom »Erlösergott « spricht.

24 Vgl. u.a. Dtn 32151 Reg 1019 [LXX] Est 511 Makk 4303 Makk 629 Ps [LXX] 235 2456136646941 Weish 167 Mi 77 Hab 318 Jes 12245156211.

25 Vgl. M. Dibelius-H. Conzelmann, Past (s. Anm. 22), 75; J. Jeremias, Briefe (s. Anm. 8), 51; mit Verweis auf K. H. Schelkle (Theologie des Neuen Testaments II, Düsseldorf 1973, 217) auch P. Trummer, Paulustradition (s. Anm. 1), 195.

26 Vgl. G. Fohrer, ThWNT VII, 1013; N. Brox, Past (s. Anm. 5), 232; J. Jeremias, Briefe (s. Anm. 8), 51. 
prägte Terminologie aufgenommen ist ${ }^{27}$, ist auch für den Gebrauch des Titels $\sigma \omega \tau \eta \dot{\varrho} \varrho$ für Jesus der Einfluß der geläufigen Verwendung dieses Titels in der Gottesverehrung und im Herrscherkult der griechisch-helle-

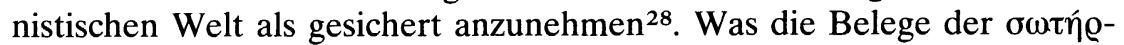
Bezeichnung für »Christus Jesus « angeht, so steht schon die in den Grußzuschriften nur Tit 14 gewählte Apposition »unser Retter (vgl.

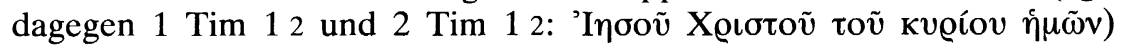

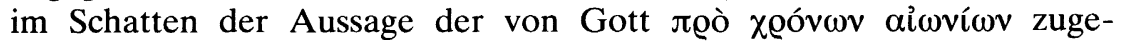
sprochenen Hoffnung auf »ewiges Leben«, zugeordnet der dem Apostel anvertrauten Verkündigung im »Auftrag Gottes, unseres Retters « (Tit $12 \mathrm{f}$.). Noch klarer und eindringlicher wird an den anderen Stellen diese

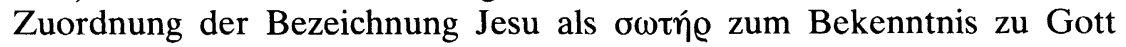
als »Heilbringer « formuliert. Hat zwar nach 2 Tim 110 »die Gnade « (v. 9) sich »durch die Erscheinung unseres Retters Christus Jesus « offenbart, so erfüllt sich darin doch »nur « der Heilsplan Gottes; Gott ist es,

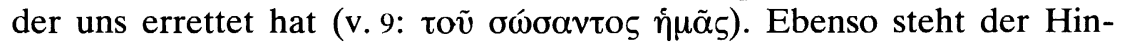
weis auf die Funktion Jesu als Retter Tit 36 in deutlicher Abhängigkeit und Unterordnung unter die von Gott selbst an uns vollzogene

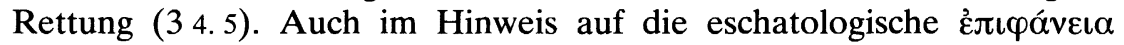
»unseres Retters Jesus Christus « Tit 213 wird diese Rettung Gottes rettender Tat zugeschrieben (vgl. Tit 211$)^{29}$. Jesu richterlich-rettende Funktion ist verknüpft mit der Erscheinung der »Herrlichkeit unseres großen Gottes $\ll^{30}$.

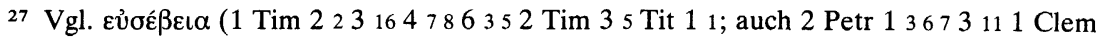

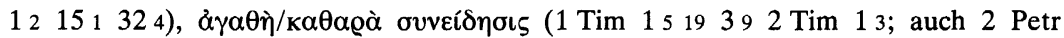

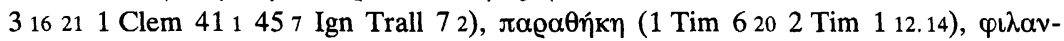

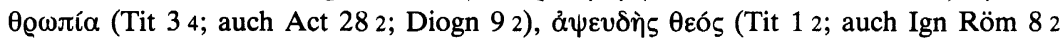

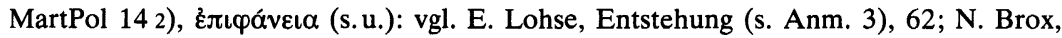
Past (s. Anm. 5), 64 f. Zu owtí@ vgl. auch 1 Clem 593 Ign Eph 11 Magn praescr.; Phld 92 Sm 71 Pol 2 Phil praescr.

28 Vgl. N. Brox, Past (s. Anm. 5), 232; F. Stolz, THAT I, 790; mit Belegen M. DibeliusH. Conzelmann, Past (s. Anm. 22), 74-77; W. Foerster, ThWNT VII, 1005-1012. Eine bewußt antithetische Titulierung Jesu Christi als $\sigma \omega \tau \eta \dot{\varrho}$ im Gegenüber zu den »Sotäres« der nichtchristlichen Umwelt (so C. Spicq, Épîtres [s. Anm. 7], 315; J. Jeremias, Briefe [s. Anm. 8], 51) ist jedoch wegen der umfassenden Einordnung der Heilsbedeutung Jesu in den göttlichen Heilsplan und Heilswillen bei unserem Verf. wenig wahrscheinlich (vgl. auch M. Dibelius-H. Conzelmann, a.a.O., 77; P. Trummer, Paulustradition [s. Anm. 1], 195).

29 Vgl. H. Windisch, Zur Christologie der Pastoralbriefe, in: ZNW 34, 1935, 213-238, hier 225.

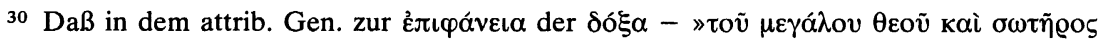

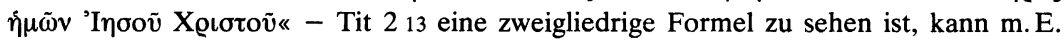
nicht zweifelhaft sein, und zwar nicht nur, weil eine Bezeichnung Jesu als des "großen Gottes« im NT einmalig wäre (vgl. J. Jeremias, Briefe [s. Anm. 8], 73), sondern v.a. 


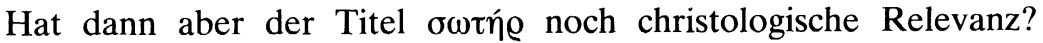
Kann man aus der »doppelten Verwendbarkeit des Titels« auf eine »Einheit zwischen Gott und Jesus Christus in ihrem Heilswillen und -tun « schließen ${ }^{31}$; oder ist eine Unterordnung Jesu Christi unter Gott gegeben, so daß Jesus Christus als $\sigma \omega \tau \eta \dot{\varrho}$ »keine selbständige Würdestellung (beansprucht)«, er vielmehr »den Erlösungsplan Gottes (erfüllt)«, folglich

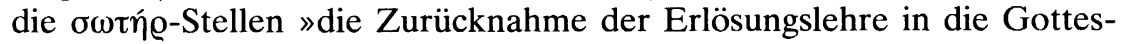
lehre (bestätigen)«32? Eigenständige christologische Relevanz könnte man diesem Titel in der Verwendung für Jesus in der Tat dann nicht absprechen, ließe sich mit N. Brox die Behauptung wagen, der Titel sei »in seiner Anwendung auf Gott wie auf Jesus Christus nun völlig durch seine Beziehung auf die Erlösungstat Gottes in Kreuz und Auferstehung Jesu Christi geprägt « ${ }^{33}$. So sehr dies für den Fall zu bejahen ist, daß man wichtige Passagen der Past über die heilsmittlerische Funktion des Todes Jesu (vgl. 1 Tim 26 Tit 2 14; auch 1 Tim 115) als die »Retter «Aussagen interpretierende Ergänzungen nimmt ${ }^{34}$, so wenig wird doch damit die unübersehbare und vom Verf. ganz bewußt vorgenommene Unterordnung der »Retter «-Funktion unter die »Souveränität Gottes « ${ }^{35}$ beseitigt.

Nach den Past kann man von Jesus als »unserem Retter « also nur sprechen, wenn man zugleich von Gott als »unserem Retter spricht. In dieser funktionalen Hinordnung des Heilswerkes Jesu auf die von Gott initiierte und bleibend von ihm getragene Heilsgeschichte wird Jesu Stellung nicht entwertet oder gar aufgehoben; vielmehr macht der Verf. damit deutlich, daß mit Jesus Gottes letztes Wort an die Menschen

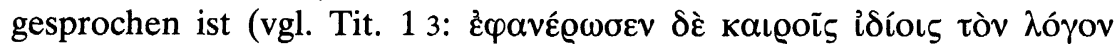

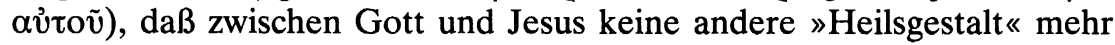

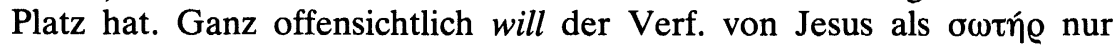
sprechen, wenn gleichzeitig deutlich gemacht wird, daß dieses Heil in Christus Jesus grundsätzlich Verwirklichung des göttlichen Heilswillens ist. Dann ist aber eine innere Verknüpfung gegeben: Wie die Botschaft vom »Retter " Jesus die Gewißheit des Heilswillens Gottes zur Voraussetzung hat, so ist umgekehrt das Vertrauen auf Gott als unseren Retter begründet und verankert in der in Christus Jesus erfolgten und noch zu vollendenden Verwirklichung des Heils.

wegen der betonten Herausstellung Gottes als des Heilbringers in den Past (vgl. H. Windisch, Christologie [s. Anm. 29], 226; V. Hasler, Epiphanie [s. Anm. 20], 200; W. Metzger, Christushymnus [s. Anm. 8], 43-45. 73-75). Vgl. aber Ign Eph 11153 18 2; Trall 71 Röm 33 Sm 101 Pol 83.

31 N. Brox, Past (s. Anm. 5], 233.

3.2 V. Hasler, Epiphanie (s. Anm. 20), $201 \mathrm{f}$.

33 N. Brox, Past (s. Anm. 5), 233.

34 Vgl. N. Brox, Past (s. Anm. 5), 162.

35 Vgl. H. Windisch, Christologie (s. Anm. 29), 226. 


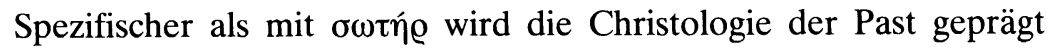

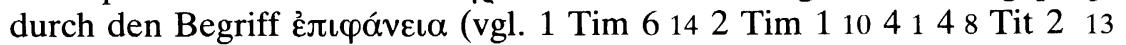
vgl. Tit 21134 ), der, ebenfalls der griechisch-hellenistischen Umwelt entnommen ${ }^{36}$, eine wichtige und umfassende Funktion hat ${ }^{37}$. Der be-

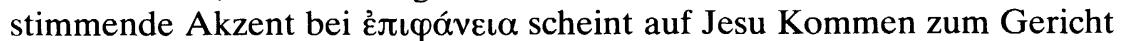
zu liegen. So wird 1 Tim 614 der Apostelschüler im Rahmen des paränetischen Abschnittes 611-16 ${ }^{38}$ verpflichtet auf die Bewahrung der

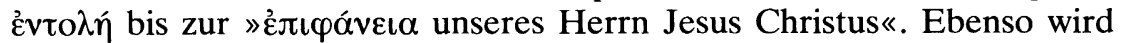
im beschwörenden "Schlußappell des vor seiner Hinrichtung stehenden Martyrerapostels an seinen zurückbleibenden Lieblingsschüler und dessen

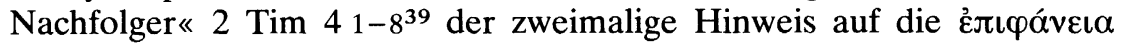
Jesu Christi auf dessen »Erscheinen « zum Gericht bezogen (vgl. bes. die Verknüpfung mit dem »Gericht über Lebende und Tote « v. 1 und die

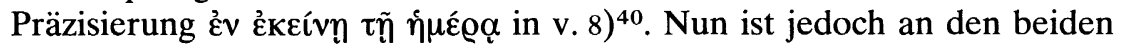

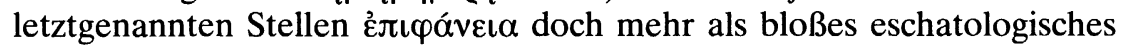
»Datum«; der Ausdruck ist viel weiter gespannt, er schließt die Gegenwart als die für das Bestehen im Gericht entscheidende Zeit mit ein. Dies wird überdeutlich aus der Verknüpfung der »Epiphanie « mit den Mahnungen des Apostels an seinen Nachfolger im Amt der Bewahrung der »gesunden Lehre« (2 Tim 43 ). V.a. 2 Tim 48 belegt dies: »Pls « blickt zwar auf das Endgericht aus; die Zeit der Entscheidung dagegen ist die Gegenwart. Und deshalb kann »der Apostel« davon sprechen, daß der »Kranz der Gerechtigkeit « für ihn bereits bereitliegt,

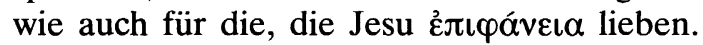

Es geht also darum, die દ̇ंıৎáveı Jesu als die das Leben bestimmende und prägende Wirklichkeit zur Geltung kommen zu lassen, schon jetzt ihr entprechend $\mathrm{zu}$ leben. Im Gegenüber $\mathrm{zu}$ einer rein futurischen Deutung auf das »Erscheinen« zur Parusie ist der Gegen-

36 Vgl. 2 Makk 3241222141515273 Makk 295 , auch 2 Clem 12117 4. Im NT nur noch 2 Thess 28 (in Verbindung mit $\pi \alpha \varrho o v \sigma i \alpha$ ).

Zur Übersicht über Belege und Verwendung v. a. E. Pax, EПIФANEIA. Ein religionsgeschichtlicher Beitrag zur biblischen Theologie, MThS I, 10, München 1955; vgl. auch D. Lührmann, Epiphaneia. Zur Bedeutungsgeschichte eines griechischen Wortes, in: G. Jeremias u.a. (Hrsg.), Tradition und Glaube. FS K. G. Kuhn, Göttingen 1971, 185-199, bes. $187-195$.

37 Vgl. E. Pax, ЕПІФANEIA (s. Anm. 36), 245; P. Trummer, Paulustradition (s. Anm. 1), 200.

38 Dazu E. Käsemann, Das Formular einer neutestamentlichen Ordinationsparänese, in: ders., Exegetische Versuche und Besinnungen I, Göttingen 61970, 101-108, der den Abschnitt als vom Verf. übernommene Einheit erklärt; mit ihm N. Brox, Past (s. Anm. 5), 212.

39 V. Hasler, Die Briefe an Timotheus und Titus (Pastoralbriefe), ZBK, NT 12, Zürich 1978, 76; vgl. N. Brox, Past (s. Anm. 5), 262 f.

$40 \mathrm{Vgl}$. P. Trummer, Paulustradition (s. Anm. 1), 201. 


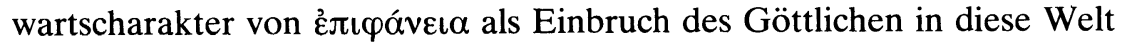
mitzubedenken. ${ }^{41}$

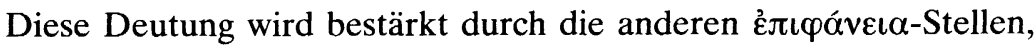
in denen sicher nicht zufällig auch der Titel $\sigma \omega \tau \eta \dot{\varrho}$ steht. Die Erwartung der »Epiphaneia der Herrlichkeit des großen Gottes und unseres Retters Jesus Christus« (Tit 2 13) steht unter der Gewißheit, daß »die für alle

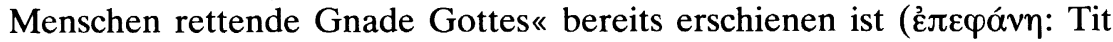

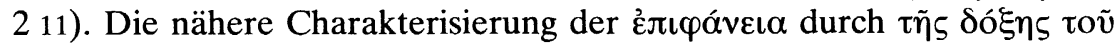

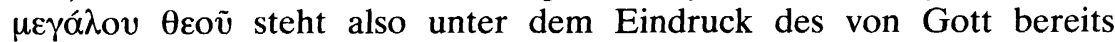

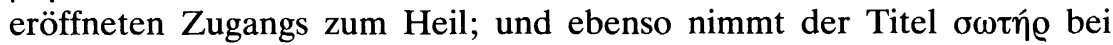
Jesus Christus die Gegenwart bereits mit auf ${ }^{42}$, wie vor allem die noch zu besprechende Ergänzung durch den traditionellen Vers Tit 214 bestätigt. Der zweifellos auch enthaltene eschatologische Aspekt ist verankert in der durch den Heilswillen Gottes und dessen Erfüllung in der Person

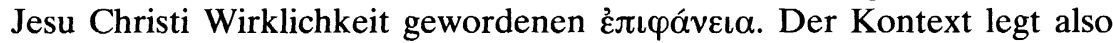

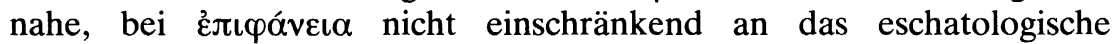
»Erscheinen « Jesu zu denken, sondern an das gesamte Christusgeschehen (als Bestandteil der göttlichen Heilszuwendung).

Diese Deutung kann sich auch stützen auf Tit 3 3-7. Die Hoffnung auf »ewiges Leben« (v. 7) ist deswegen keine unbegründete Zukunfts-

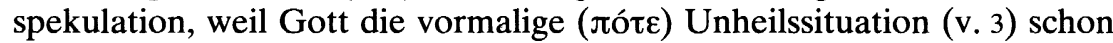

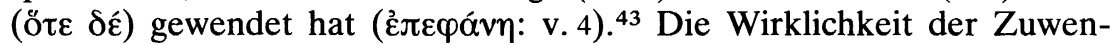

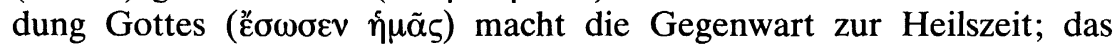
gläubige Vertrauen auf die Zukunft hat seinen tragenden Grund in der bereits erfolgten »Wiedergeburt « und im Beistand des Heiligen Geistes (v. 5). ${ }^{44}$ Jesus steht als »Retter « in dieser Linie der Selbstoffenbarung

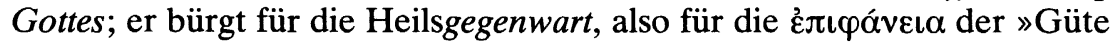
und Menschenfreundlichkeit Gottes« (v. 4). ${ }^{45}$

41 Vgl. auch O. Merk, Glaube und Tat in den Pastoralbriefen, in: ZNW 66, 1975, $91-$ 102, hier 98-100. Der Verf. übersetzte »bewußt christliche Zukunftserwartung in seine Gegenwart hinein« (100).

42 Vgl. P. Trummer, Paulustradition (s. Anm. 1), 201, der jedoch stärker den Ausblick auf die »endzeitliche Epiphanie « betonen zu wollen scheint; ebenso D. Lührmann, Epiphaneia (s. Anm. 36), 200.

43 Damit ist sicher nicht nur die »Menschwerdung " gemeint; gegen E. Pax, EMIФANEIA (s. Anm. 36), 243.

44 Vgl. U. Luz, Rechtfertigung (s. Anm. 17), 372, Anm. 21 (»Rettung als in der Vergangenheit oder Gegenwart liegende Heilserfahrung «, mit Hinweis u.a. auf 2 Tim 19 und Tit 3 5); auch 376-379 (378 Anm. 37: die Tätigkeit des Verf. werde u.a. sichtbar an der Formulierung દ̇

Zu Tit 3 4-7 als einem Stück »festformulierte(r) Taufparänese der hellenistischen Christenheit « E. Käsemann, Titus $34-7$, in: ders., Exegetische Versuche und Besinnungen I (s. Anm. 38), 298-302, bes. $298 \mathrm{f}$.

$45 \mathrm{Vgl}$. H. Windisch, Christologie (s. Anm. 29), $225 \mathrm{f}$. Wenn Windisch hier auf »die für die Theologie der Past charakteristische Zurückdrängung der Beteiligung Jesu an dem 
»Epiphaneia « umgreift mehr als nur einen einzelnen Punkt, etwa die »Erscheinung « Jesu zum Gericht. Der Begriff umfaßt die Gesamtheit des helfenden Eingreifens Gottes, seines Retter-Seins; und er umfaßt deshalb auch das Christusgeschehen als ganzes, nicht nur einzelne Stationen, auch wenn an manchen Stellen der eschatologische Aspekt im Vordergrund stehen mag. Ėंı Zusammenhang und die Bindung an den Titel $\sigma \omega \tau \eta \dot{\varrho}$ (vgl. bes. Tit 11-4).

Damit findet auch der bei einer einseitigen Betonung des eschato-

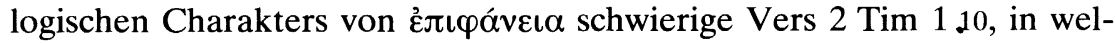
chem im Gegensatz dazu und als einziges Mal von der Inkarnation als $\dot{\varepsilon} \pi \iota \varphi \alpha ́ v \varepsilon \iota \alpha$ gesprochen würde ${ }^{46}$, eine sinnvolle Erklärung. Wiederum ist charakteristisch die Verknüpfung mit dem Hinweis auf die durch Gott schon bewirkte »Rettung « einerseits (v. 9) und die Qualifizierung Jesu als $\sigma \omega \tau \eta \dot{\varrho}$ andrerseits (v. 10). Gegen eine einseitige Festlegung der

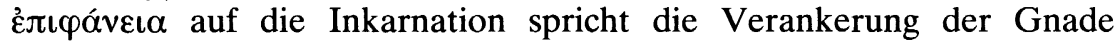

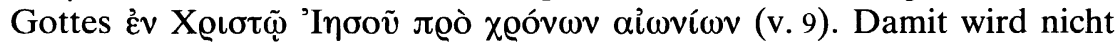
nur der "göttliche Heilsratschluß « als "präexistent " gesehen ${ }^{47}$, sondern auch die konkrete Verwirklichung in Christus Jesus in den Heilsplan Gottes mithineingenommen. Wenn aber Gottes Heilswille in Jesu

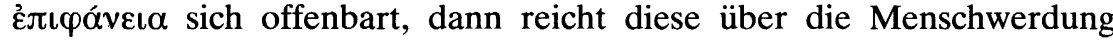
hinaus. »Epiphaneia «, verstanden als das »helfende Eingreifen ${ }^{48}$, ist "nicht etwas Abgeschlossenes, Statisches, sondern befindet sich in Bewegung « 49 . Sie ist kein Ereignis »an sich «, sondern stellt eine Beziehung her; sie ist Eröffnung der Heilssphäre Gottes für die

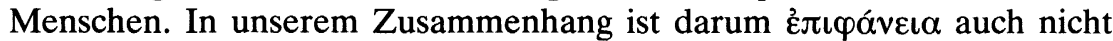
nur bezogen auf die Inkarnation, sondern umgreift neben Tod und

Heilswerk, sowie eine starke Betonung der Souveränität Gottes « verweist, dann unterstellt er, daß man in beiden - Souveränität Gottes und Beteiligung Jesu - einen Gegensatz oder zumindest eine Konkurrenz sehen muß. Ist aber in der Hinordnung des Heilswerkes Jesu Christi auf den Heilswillen Gottes nicht gerade das Gegenteil der Fall?

46 Vgl. J. Jeremias, Briefe (s. Anm. 8), 50. Vgl. aber auch den Hinweis auf Tit 211 und Tit 34 bei C. Spicq, Épîtres (s. Anm. 7), 716, und N. Brox, Past (s. Anm. 5), 231.

47 Vgl. N. Brox, Past (s. Anm. 5), 230.

48 D. Lührmann, Epiphaneia (s. Anm. 36), 198.

49 E. Pax, EПIФANEIA (s. Anm. 36), 233. 232-235; die Ausrichtung auf »die zweite Epiphanie« (234; vgl. auch P. Trummer, Paulustradition [s. Anm. 1], 201) engt das Bezugsfeld jedoch wiederum zu stark ein. Úberhaupt scheint die Rede von der »ersten « und "zweiten« Epiphanie, bezogen auf Inkarnation und Parusie (vgl. etwa auch V. Hasler, Epiphanie [s. Anm. 20], 199; anders 200: "So sprechen die Hirtenbriefe entgegen einer vorschnellen Interpretation auch nicht von einer ersten und einer zweiten Epiphanie ... «), der Intention des Verf. der Past nicht angemessen. 
Auferweckung ${ }^{50}$ auch die bleibende Gegenwart in der Verkündigung des »Evangeliums « (vv. 10 fin. 11f.). Um dessen »Bewahrung « bis zu »jenem Tag« muß es dem in der Nachfolge des Apostels stehenden Schüler gehen (vv. 13f.). »Das empfangene Heil ist durch die Kontinuität des Evangeliums bleibende Gegenwart für das Leben der Gemeinde. «51

\section{Die Aufnahme alten Traditionsgutes}

Daß die z.T. älteste Christologie bezeugenden Traditionsstücke, die vom Verf. aufgenommen worden sind, den Charakter der Christologie der Past entscheidend prägen, wurde bereits eingeräumt. Lassen sie sich

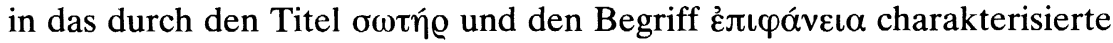
Grundgerüst einordnen?

Dafür spricht eindeutig schon die Beobachtung, daß von den 2 Belegen mit Aussagen zur heilsmittlerischen Funktion des Todes Jesu

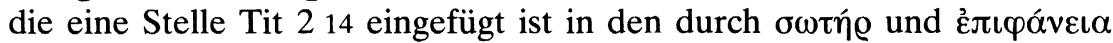
geprägten Abschnitt Tit 211-15. Die Stellung Jesu als $\sigma \omega \tau \eta$ @ ist in der »Selbsthingabe für uns « expliziert; diese steht nicht für sich, sondern bestätigt zugleich den »für alle Menschen « offenbar gewordenen

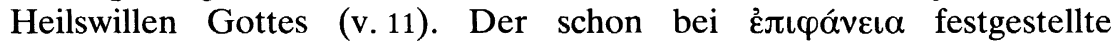
Gegenwartsbezug wird auch für die Hingabe-Formel in dem angefügten

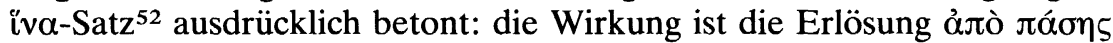

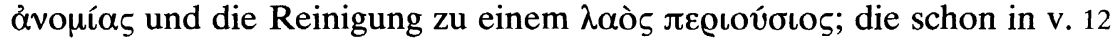

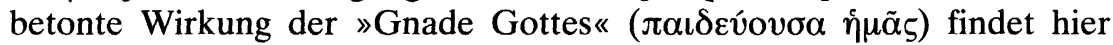
ihre Abrundung. Der Autor der Past ist somit an dieser Formel weniger interessiert als einer christologischen Spitzenaussage, als vielmehr daran, daß die Kontinuität des göttlichen Heilshandelns über die Selbsthingabe Jesu »für uns« die Gemeinschaft der Gläubigen bestimmt (vgl. v. 15).

Ähnlich verhält es sich mit der Úbernahme der Hingabe-Formel 1 Tim 26, die mit dem v. 5 fin eingeschobenen őv $\theta \varrho \omega \pi 0 \varsigma$ X 'I der Annahme, das dem Verf. vorliegende Überlieferungsstück habe bereits die Verse 5 und 6 umfaßt $^{53}$, hat als wahrscheinlicher zu gelten,

50 Vgl. H. Windisch, Christologie (s. Anm. 29), 224, jedoch mit einseitiger Festlegung auf die Auferweckung.

51 O. Merk, Glaube (s. Anm. 41), 98.

52 Nach K. Wengst läßt sich nicht entscheiden, ob diese Apposition schon zur traditio-

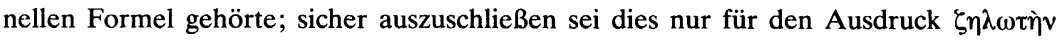
к $\alpha \lambda \tilde{\omega} v$ है $\mathrm{\gamma} \omega \nu$ (Christologische Formeln und Lieder des Urchristentums, StNT 7, Gütersloh $\left.{ }^{2} 1973,73\right)$.

53 So M. Dibelius-H. Conzelmann, Past (s. Anm. 22), 34; N. Brox, Past (s. Anm. 5), 128; J. Jeremias, Briefe (s. Anm. 8), 20. 
daß erst der Autor die $\varepsilon \tilde{i} \zeta$-Akklamation mit der Selbsthingabe-Formel verknüpft hat. Dafür spricht, daß offensichtlich die ausdrückliche

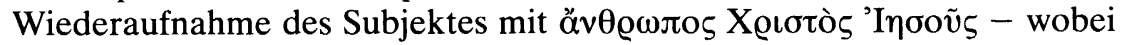
antidoketistische ${ }^{54}$ Tendenzen in der betonten Voranstellung von őv $\theta \varrho \omega \pi \circ 5$ durchaus impliziert sein dürften ${ }^{55}$ - nicht nur als Präzisierung, sondern auch als bei der Verbindung der beiden Traditionsstücke notwendige Ergänzung anzusehen ist. Die beiden Formeln stehen sodann nicht spannungslos nebeneinander; während die عiَऽ-Akklamation hier im Gegensatz zu ähnlichen Formeln (wie 1 Kor $85 \mathrm{f}$. und Eph $45 \mathrm{f}$.), wo die uneingeschränkte Stellung Jesu als кú betont wird ${ }^{56}$, ein deutliches Hervortreten der Person Gottes aufweist, die eben auch im angeschlossenen christologischen Bekenntnis zu Jesus

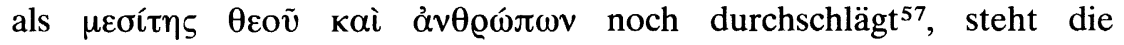
soteriologische Christologie - die »Befreiung « der Menschen ist Frucht der Selbsthingabe Jesu - im Zentrum des zweiten Zitates. Für die These

Obwohl nach A. T. Hanson, Tradition (s. Anm. 6), 63f, dem Abschnitt 1 Tim 2 1-6 ein liturgisches Gebetsformular zugrundeliegt (vergleichbar 1 Clem 59-61), erklärt er die Verse 5 und 6 als zwei selbständige Traditionen, die erst vom Verf. zusammengefügt wurden.

54 Das Adjektiv "(anti)doketistisch « ist übernommen von P. Weigandt, Der Doketismus im Urchristentum und in der theologischen Entwicklung des zweiten Jahrhunderts, Diss. Heidelberg 1961 (masch.), 2 Bde (zur Begründung Bd. II, S. 1, Anm. 3); vgl. auch G. Richter, Die Fleischwerdung des Logos im Johannesevangelium, in: ders., Studien zum Johannesevangelium (hrsg. v. J. Hainz), BU 13, Regensburg 1977, 149198 , hier $183 \mathrm{ff}$.

$55 \mathrm{H}$. Windisch will dies ausschließen, da nirgends gesagt sei, »daß die Irrlehrer auch eine falsche Christologie vortragen« (Christologie [s. Anm. 29], 229); N. Brox laßt die Frage offen (Past [s. Anm. 5], 128); K. Wengst plädiert dafür, daß der Verf. »gegenüber doketischen Tendenzen die Menschlichkeit dessen betonen (will), der sich dahin-

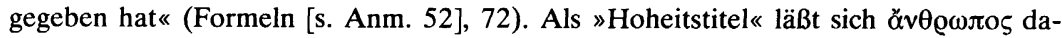
gegen kaum verstehen (gegen P. Trummer, Paulustradition [s. Anm. 1], 197).

Gegen A. Grillmeier (Art. Doketismus, in: LThK $^{3}$ III, 470 f.) stellt P. Weigandt fest: "Von Doketismus ist in den Pastoralbriefen nicht eine Spur zu finden « (Doketismus [s. Anm. 54], Bd. II, 1, Anm. 8); gegenüber der von Weigandt behaupteten Exklusivität der Auseinandersetzung mit dem Doketismus im NT im Joh-Ev und in den beiden ersten Joh-Briefen (a.a.O., Bd. I, 101-107) ist mit der Bestimmung des Zieles des Doketismus, nämlich einer »Eliminierung der menschlichen Seite Jesu Christi« (ebd. 157), auch für unsere Stelle eine antidoketistische Spitze gut zu begründen.

56 Vgl. F. Hahn, Christologische Hoheitstitel. Ihre Geschichte im frühen Christentum, Göttingen ${ }^{3} 1966,122$; K. Wengst, Formeln (s. Anm. 52), 135. 136-142.

$57 \mathrm{Vgl}$. A. Oepke, ThWNT IV, 623.

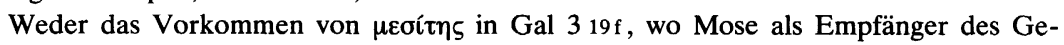
setzes so bezeichnet wird, kann als Parallele gelten, noch auch das Hebr 869151224 formulierte Bekenntnis zu Jesus als $\mu \varepsilon \sigma i ́ t \eta s$ des »(neuen) Bundes«; vgl. dazu K. Wengst, Formeln (s. Anm. 52), 142f.; V. Hasler, Epiphanie (s. Anm. 20), 203 f. 
einer vom Verf. bewußt vorgenommenen Hinordnung der Selbsthingabe-Formel von v. 6 auf die Funktion der Heilsmittlerschaft des Heilswillens Gottes von v. 5 spricht auch der vorangehende Kontext. Mit

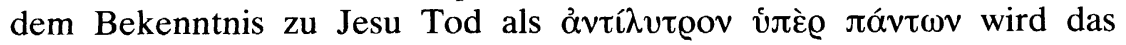

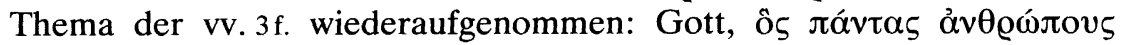
$\theta \varepsilon \dot{\lambda} \varepsilon \iota \sigma \omega \theta \tilde{\eta} v \alpha \iota$. Im Verständnis des Autors ist darum die SelbsthingabeFormel $^{58}$ nicht ein selbständiges christologisches Datum; sie ist vielmehr Explikation des übergeordneten und dafür unentbehrlichen Heilswillens Gottes. Die Bedeutung des Todes Jesu liegt somit darin, daß sich in ihm der verborgene göttliche Heilswille als »konkret historisches Ereignis« offenbart hat. ${ }^{59}$

In diese Deutung fügt sich auch das »hart « ${ }^{60}$ angeschlossene tò

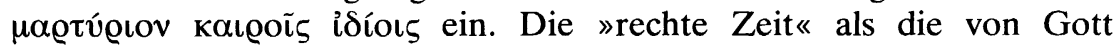
festgesetzte und bestimmte Zeit ist wie 1 Tim 615 und Tit 13 ein »heilsgeschichtlicher Terminus « 61 , der den Tod Jesu qualifiziert als »Zeugnis« und Unterpfand der Verwirklichung des göttlichen Heilsrat-

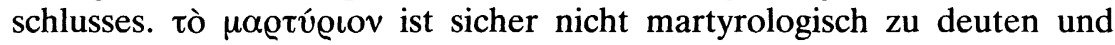
auf den Tod Jesu zu beziehen ${ }^{62}$, sondern bezeichnet die in diesem Sterben sich dokumentierende und bleibend gültige Heilszusage Gottes. Stärker als die Vergangenheit sind gleicherweise die Gegenwart und die Zukunft als die für das Heil relevanten »Zeiten « betont. Der Gegenwartscharakter des Heils wird zudem hervorgehoben durch die angeschlossene Paulusanamnese in v. $7^{63}$. Die Aufgabe des »Pls« liegt nicht in der »Verlängerung des Zeugnisses Jesu « ${ }^{64}$; mit der Bestimmung

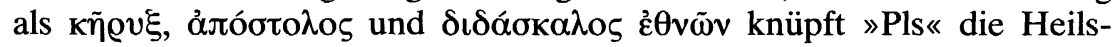
botschaft untrennbar an sein Ev (vgl. 1 Tim 1112 Tim 18-11 2 8; auch Tit 13). Nur über die Bewahrung des Ev als der »gesunden Lehre«

58 Zur Frage nach dem traditionsgeschichtlichen Bezug zu Mk 1045 (= Mt 20 28) ist hier soviel als gesichert vorauszusetzen, daß ein »Überlieferungszusammenhang « anzunehmen ist; vgl. N. Brox, Past (s. Anm. 5), 128; H. Patsch, Abendmahl und historischer Jesus, CThM A 1, Stuttgart 1972, 177. 329, Anm. 209.

59 Vgl. V. Hasler, Epiphanie (s. Anm. 20), 205. „Das als Verheißung gegebene Wort Gottes ist sichtbar geworden « (ders., Past [s. Anm. 39], 23).

$60 \mathrm{Vgl}$. V. Hasler, Epiphanie (s. Anm. 20), 205.

${ }^{61}$ M. Dibelius-H. Conzelmann, Past (s. Anm. 22), 35; vgl. K. Wengst, Formeln (s. Anm. 52), 72.

62 Gegen diese etwa von G. Holtz, Past (s. Anm. 8), 62, geäußerte These u.a. N. Brox, Past (s. Anm. 5), $128 \mathrm{f}$.

63 Zu den Pls-Anamnesen der Past vgl. P. Trummer, Paulustradition (s. Anm. 1), 116132.

64 So P. Trummer, Paulustradition (s. Anm. 1), 120 (vgl. 120-123).

Vgl. O. Merk, Glaube (s. Anm. 41), 100: »Der Verfasser spricht offenbar bewußt von der bleibenden Gegenwart des Evangeliums, nicht etwa von der bleibenden Gegenwart Jesu. « 
(2 Tim 43 Tit 1921 1 $^{65}$ geschieht die Vermittlung des Christusgeschehens als Heilsgeschehen. ${ }^{66}$

Mit der Úbernahme der alten Tradition der Selbsthingabe Jesu bindet der Autor der Past den ohne Zweifel zentralen Gedanken des

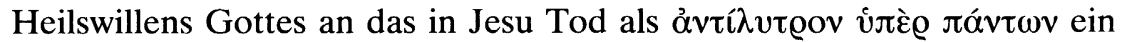
für alle Mal geschehene, historisch einmalige und unwiederholbare Ereignis. Durch die Einbindung auch dieses Sühneleidens in die ganz der Verfügung Gottes unterstellte Heilsgeschichte wird die soteriologische Bedeutung des Todes Jesu zwar einerseits relativiert, andrerseits aber auch präzisiert und untermauert, insofern das in Vergangenheit, Gegenwart und Zukunft sich ereignende Heilsgeschehen als zentralen Ort den Sühnetod Jesu miteinschließt.

Ähnlich verhält es sich mit der ebenfalls durch den Kontext interpretierten »Aussage über Jesu Sendung und Heilsfunktion « ${ }^{67} 1 \mathrm{Tim}$

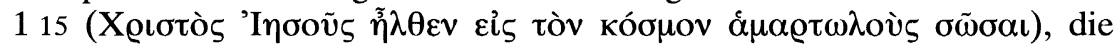
schon in sich gegenüber dem vergleichbaren Jesuswort Lk $1910(\eta \tilde{\eta}) \lambda \varepsilon v$

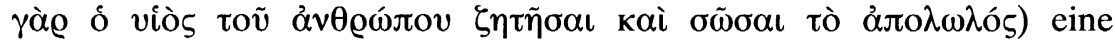
allgemeinere und charakteristisch universalistische Tendenz aufweist

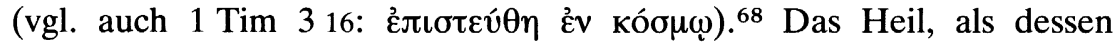
»erster « Nutznießer und damit »Vorbild « für alle Glaubenden »Pls« sich vorstellt (1 Tim 1 15b.16), ist Ergebnis des vom Kyrios (vgl. v. 14) geschenkten »Erbarmens « (v. 13b: $\grave{\eta} \lambda \varepsilon \dot{\eta} \theta \eta v)$, nicht aber nur durch Jesu Leben und Sterben vermitteltes Heil. Wieder ist der Blick nicht rückwärts gewendet »auf ein bereits vollbrachtes Heilswerk Christi«69; Jesu »Kommen « ist vielmehr die das gegenwärtige Vertrauen und die Zuversicht auf das ewige Leben tragende Wahrheit. Nimmt man als das assoziierende Stichwort für die Einführung der Paulusanamnese das

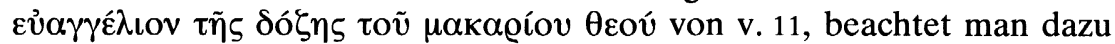

65 Vgl. O. Merk, Glaube (s. Anm. 41), 94f; J. Wanke, Paulus (s. Anm. 21), 170-173.

66 Die harte Aussage von V. Hasler, Epiphanie (s. Anm. 20), 202, zu 2 Tim 1 10, daß »Inhalt dieses Evangeliums . . . nicht der Heilscharakter des Sterbens und Auferstehens Jesu (ist), sondern die Bezeugung des ewigen Heilswillens Gottes, daß alle Menschen gerettet werden sollen «, somit »Karfreitag und Ostern lediglich Kerygma, kein Heilsfaktum (sind) «, trifft insofern zu, als das Heil jetzt wesenhaft an den Glauben an das Ev gebunden ist. Da jedoch dieses Ev wiederum nicht eine abstrakte Größe ist, sondern inhaltlich eindeutig auf die Realisierung des göttlichen Heilswillens in der konkret geschichtlichen Offenbarung in Christus Jesus Bezug nimmt, kann man eine Trennung von »Kerygma « und »Heilsfaktum« kaum so streng durchhalten.

67 Vgl. N. Brox, Past (s. Anm. 5), 111.

${ }^{68}$ Lk 1910 hebt auf die Heilsbedeutung des gesamten irdischen Wirkens Jesu ab (vgl. G. Schneider, Das Evangelium nach Lukas, ÖTK 3, 1. 2, Gütersloh/Würzburg 1977, 378); 1 Tim 115 wird schon »die nachgeschichtliche Heilandstätigkeit des Herrn« miteinbezogen. Vgl. auch V. Hasler, Past (s. Anm. 39), 16.

69 Mit V. Hasler, Epiphanie (s. Anm. 20), 203. 


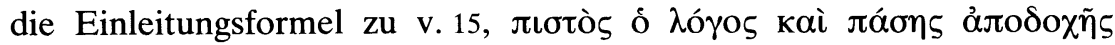
$\alpha{ }^{\prime} \xi\llcorner O 5$, dann verbürgt das »Wort vom Sünder-rettenden-Kommen Christi « als die den Glauben der Kirche tragende Wahrheit die Kraft des Evangeliums $^{70}$.

Es bestätigt sich damit das Urteil von Dibelius-Conzelmann: »Wenn die Past in geprägten Wendungen vom Heil reden, verknüpfen sie regelmäßig damit die aktuelle Anwendung für die Gegenwart. « ${ }^{71}$

\section{Die Übernahme pln Tradition}

Im Rahmen der Ermahnungen des »Apostels « an den in seiner Nachfolge stehenden Schüler wird 2 Tim 21-13 der Auftrag zur »Weitergabe« der vom Apostel überkommenen Botschaft (v. 2) und die Aufforderung zum »Mitleiden« (v. 3) im Abschnitt der vv. 8-13 in Sicht auf das Ev des Apostels und seine daraus resultierenden Leiden vertieft. Dieses sein Ev ist nach v. 8 die Botschaft von Jesus Christus,

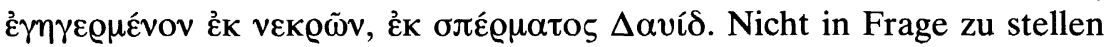
ist die inhaltliche Zusammengehörigkeit von 2 Tim 28 und Röm $13 \mathrm{f}$; wohl aber wird die Frage kontrovers beantwortet, ob für 2 Tim 28 eine direkte Abhängigkeit von der Röm-Stelle anzunehmen sei. Gegenüber den Befürwortern einer traditionsgeschichtlichen Unabhängigkeit ${ }^{72}$ hat mit P. Trummer die These mehr Wahrscheinlichkeit für sich, daß der Verf. der Past an dieser Stelle Röm $13 \mathrm{f}$. in charakteristischer Abänderung rezipiert ${ }^{73}$, wofür v.a. der Hinweis auf die Davidsherkunft spricht ${ }^{74}$.

70 Vgl. J. Wanke, Paulus (s. Anm. 21), 179; O. Merk, Glaube (s. Anm. 41), 98.

71 M. Dibelius-H. Conzelmann, Past (s. Anm. 22), 24.

${ }^{72}$ Dabei läßt diese Erklärung noch viele Variationen zu: U. Wilckens nimmt für 2 Tim 28 »ein älteres Traditionsstadium an «, in welchem »der Blick ganz auf den Auferstandenen gerichtet (ist), der als Davidide und also als Messias ausgewiesen wird" (Der Brief an die Römer. 1. Teilband [Röm 1-5], EKK VI, 1 Zürich/NeukirchenVluyn 1978, 59; vgl. 60 f.); nach H. Schlier bezeugt 2 Tim 28 denselben Sachverhalt wie die vorpln Formel von Röm $13 \mathrm{f}$ (»Jesus Christus, geworden aus dem Samen Davids, bestellt zum Sohn Gottes aus der Auferstehung der Toten«), jedoch »unabhängig von Röm 13 f.« (Zu Röm 1 3f, in: H. Baltensweiler-B. Reicke [Hrsg.], Neues Testament und Geschichte. FS O. Cullmann, Zürich/Tübingen 1972, 207-218, hier 213f.; vgl. M. Dibelius-H. Conzelmann, Past [s. Anm. 22], 81); F. Hahn läßt zwar »die Aussage über die davidische Abstammung mit der in Röm $13 \mathrm{f}$ erhaltenen Überlieferung zusammenhảngen«, nicht aber »das Auferstehungsmotiv« (Hoheitstitel [s. Anm. 56], 258).

${ }^{73}$ P. Trummer, Paulustradition (s. Anm. 1), $202 \mathrm{f}$.; er folgert dies »aus der auch sonst im 2 Tim feststellbaren engen Anlehnung an den Röm «, wie 2 Tim 1 3-5 (s. Röm 1 8-11), 2 Tim 28 b (s. Röm 2 16) (203 mit Anm. 199). Ähnlich A. Lindemann, Paulus (s. Anm. 13), 139 mit Anm. 55.

${ }^{74}$ Vgl. dazu auch K. Wengst, Formeln (s. Anm. 52), 117. 
Gegenüber Röm $13 \mathrm{f}$. steht der Hinweis auf das »Auferwecktsein « Jesu Christi nicht als christologische Zentralaussage, sondern als Zusammenfassung des »pln « Ev; die bleibende Gegenwart Jesu als des von Gott Auferweckten ${ }^{75}$ ist sowohl Inhalt der Verkündigung als auch Grundlage der Zuversicht des "Apostels" und seines »Mitstreiters", deren Leben durch Leiden gekennzeichnet ist (vv. 3.9.). Der Verf. der Past blickt auf Ostern nicht zurück als einen »Offenbarungstermin «76; die unmittelbare Verknüpfung des Bekenntnisses mit der Person des Pls ${ }^{77}$ verweist vielmehr ebenso in die Gegenwart wie die Ausrichtung auf das »Heil« der »Auserwählten « (v. 10). Paßt aber zu dieser Deutung, die das Ev als Heilsbotschaft im wesentlichen deutet als die Botschaft von der

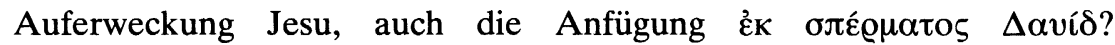
Entsprechend dem Wandel der Auferweckungsaussage - von einer christologischen Spitzenaussage über die Seinsweise des Sohnes Gottes in Macht kraft der Auferstehung von den Toten im Röm-Präskript ${ }^{78} \mathrm{zu}$ einer inhaltlichen Bestimmung des Ev des »Apostels « - ist auch für die Aussage von der davidischen Abstammung von vornherein nicht mehr das pln Verständnis der »Menschwerdung des Christus in seiner heilsgeschichtlichen Bedeutung ", d.i. als der verheißene Messias ${ }^{79}$, vorauszusetzen. Mit der Nachstellung der davidischen Abstammung hinter die Auferweckungsaussage wird aber auch die Erklärung

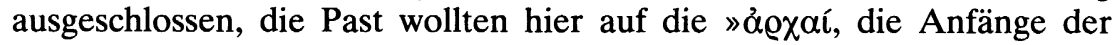
zwei Existenzweisen Jesu Christi « abheben, wir hätten also hier ein Zeugnis für das $» z w e i e x i s t e n t i a l e ~ C h r i s t u s k e r y g m a ~ « 80$ vorliegen. Daß

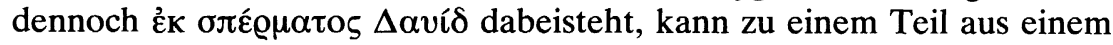
gewissen »Formzwang " aufgrund der Abhängigkeit von Röm $13 \mathrm{f}$. erklärt werden ${ }^{81}$, da der als Autor vorgestellte Pls von »meinem Evangelium « spricht. Darüber hinaus darf aber auch vermutet werden, $\mathrm{da} \beta$ die Identität des Auferweckten mit dem Irdischen als Anliegen mitschwingt, wobei wiederum antidoketistische Tendenzen mitzubeden-

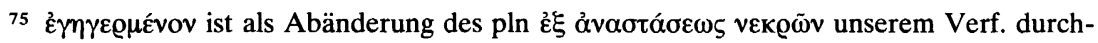
aus zuzutrauen, zumal die Auferweckungsaussage sowohl passivisch (

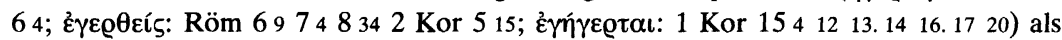
auch als Attribut Gottes (Röm 4248111091 Kor 61415152 Kor 414 Gal 111 Thess 1 10) ihm aus den Pls-Briefen nicht unbekannt sein konnte.

76 V. Hasler, Past (s. Anm. 39), 64: Ostern sei »nach göttlicher Vorherbestimmung mitten in der Menschheitsgeschichte festgelegter Offenbarungstermin «.

77 Vgl. M. Dibelius-H. Conzelmann, Past (s. Anm. 22), 81.

78 Vgl. H. Schlier, Zu Röm $13 \mathrm{f}$ (s. Anm. 72), $215 \mathrm{f}$.

79 U. Wilckens, Röm (s. Anm. 72), 65.

80 H. Windisch, Christologie (s. Anm. 29), 214-216; ihm folgt N. Brox, Past (s. Anm. 5), 242. Die Reihenfolge wird zwar als »auffällig « konstatiert, jedoch ganz offensichtlich unterbewertet.

81 Vgl. K. Wengst, Formeln (s. Anm. 52), 117. 
ken sind. ${ }^{82}$ In jedem Fall ist für die hier vorliegende Reihenfolge von Auferweckungsaussage und davidischer Abstammung Voraussetzung, daß der Hauptakzent auf ersterer liegt. Dabei steht jedoch nicht der soteriologische Aspekt im Vordergrund ${ }^{83}$ und wird die Auferweckung nicht speziell als das Zentralereignis des damit für die Menschen eröffneten Heils zur Sprache gebracht. Jesus ist als der Auferweckte der in der Verkündigung gegenwärtige Kyrios (vgl. v. 7). 2 Tim 28 ist weniger christologisch als kerygmatisch interessiert. Für den Pls der Homologumena führt die am Messias Jesus gewirkte Auferweckung zur Verkündigung des Ev; für den »Pls« der Past führt der Weg von der Verkündigung »seines « Ev zur Botschaft von der Auferweckung Jesu Christi. ${ }^{84}$

Als zweites Beispiel der Abhängigkeit von den authentischen Pls-Briefen und zugleich damit verbunden einer Neuorientierung in den

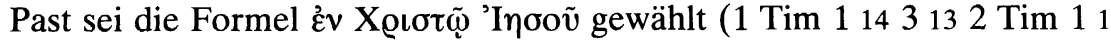
$1911321210312315)^{85}$. Schon die alleinige Verwendung dieser Form im Gegenüber zur differenzierenden Vielfalt der Pls-Briefe in der Benennung Jesu ${ }^{86}$ kann den Eindruck eines »routinemäßigen « und

82 Vgl. P. Trummer, Paulustradition (s. Anm. 1), 203 f., mit Verweis aut 1 Tím $25 \mathrm{f}$; letzteres hält er jedoch für »nicht notwendig«.

${ }^{83}$ Es erscheint keineswegs sicher, daß man, da »Jesu Weg durch die Erniedrigung die Bedingung für seine Verherrlichung (war)«, in der Auferweckungsaussage den » $\mathrm{Zu}$ sammenhang zwischen Leiden und Verherrlichung « impliziert sehen muß; dies läßt sich auch von den vv.11-13 (vgl. auch v.3) her nicht begründen (gegen N. Brox, Past [s. Anm. 5], 242).

84 Dabei ist O. Merk zuzustimmen, daß nicht Pls, sondern »allein Gott« Urheber des Ev ist. „Das Evangelium bleibt nach den Past unverfügbar ...«. »Auch 2 Tim 28 erlaubt keine andere Erklärung " (Glaube [s. Anm. 41], 96f. mit Anm. 39). Zum Thema »Der Apostel und das Evangelium « auch J. Wanke, Paulus (s. Anm. 21), 170-173.

85 Vgl. dazu J. A. Allen, The In Christ Formula in the Pastoral Epistles, in: NTS 10, 1963/64, 115-121, bes. 116-120.

Die Formel »in Christus Jesus« kann deshalb nicht für die pln Verfasserschaft in Anspruch genommen werden (gegen J. Jeremias, Briefe [s. Anm. 8], 7).

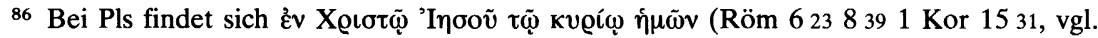

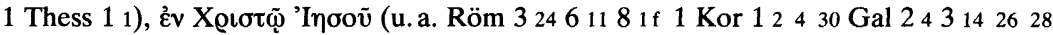

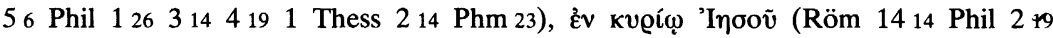

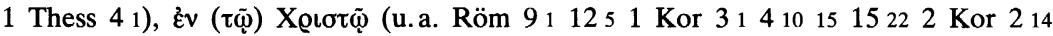
51719 Gal 217 Phil 1131 Thess 416 Phm 8 20), év кv@í $\omega$ (u.a. Röm 1621 Kor 417 722911558 Phil 3141101 Thess 38512 Phm 16).

Für Pls kann man als das alle Stellen Verbindende festhalten, »daß Christus das Lebenselement der Christen ist « (A. Wikenhauser, Die Christusmystik des Apostels Paulus, Freiburg 21956, 13; vgl. 6-14. 26-37; auch W. Thüsing, Per Christum in Deum. Studien zum Verhältnis von Christozentrik und Theozentrik in den paulinischen Hauptbriefen, NTA N.F. 1, Münster 1965, 62-66). F. Neugebauer (In Christus. Eine Untersuchung zum Paulinischen Glaubensverständnis, Göttingen 1961) differenziert zwi- 
»stereotypen « Gebrauchs erwecken ${ }^{87}$; dazu kommt, daß mit Ausnahme

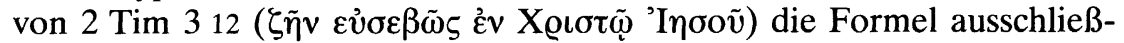
lich Substantiven zugeordnet ist. Ist mit dieser »Verarmung « gegenüber $\mathrm{Pls}^{88}$ aber auch schon der Verlust jeglicher christologischer Relevanz gegeben? Kann die bewußte Beschränkung und Engführung nicht auch zu einer Präzisierung und Profilierung der Formel führen?

Für die Feststellung P. Trummers, daß die Formel »in den Past einen eindeutig soteriologischen Bezug (hat) «89, spricht, daß 2 Tim 210 direkt vom »Heil in Christus Jesus « die Rede ist, das der Apostel durch die bereitwillige Übernahme des Leidens für die »Auserwählten « wirkt. Ebenso steht die Formel in 1 Tim 114 einerseits und 2 Tim 19 und 113 andrerseits in einem auf die Versicherung der Erfüllung der Heilszusage Gottes gerichteten Kontext. Es ist gleicherweise »die Gnade Gottes, die uns vor ewigen Zeiten in Christus Jesus geschenkt worden ist « (2 Tim 19), wie »die Gnade unseres Kyrios" (1 Tim 114), die die Heilsgewißheit der Christen trägt. Weil Gott seine Verheißungen »in Christus Jesus « wahr gemacht hat ${ }^{90}$, das Heil da ist, kann »Pls « seinen

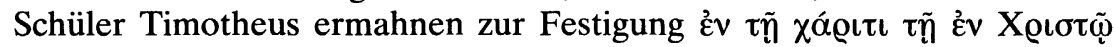
'I $\eta \sigma o \tilde{v}$ (2 Tim 2 1).

Diese Ausrichtung der Formel auf die Qualifikation des gegenwärtigen Christseins wird bestätigt durch einen Blick auf die sicher für die

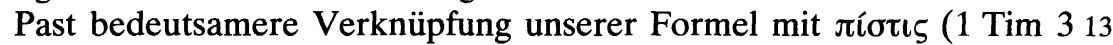

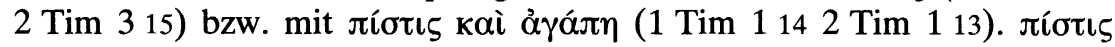
hat in den Past bereits die Bedeutung von Rechtgläubigkeit und damit zusammenhängend des rechten Glaubens gewonnen (1 Tim 1193941

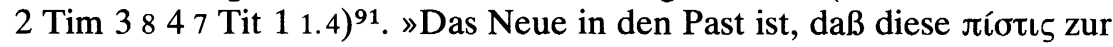

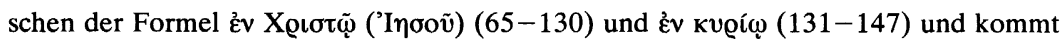
zu dem Ergebnis: „ย̉v X

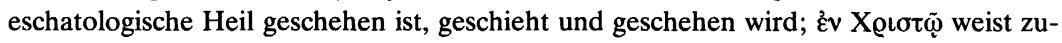
rück auf das Geschehen von Kreuz und Auferstehung und will darin die Endvollendung

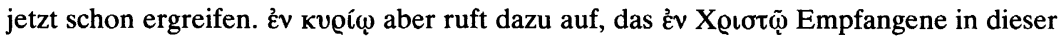
Welt zu bewähren ... Während sin Christo von der neuen, endgültigen Geschichte Gottes mit den Menschen erzählt, weist sim Herrn den Menschen von der Tat Gottes zu seiner eigenen. Beiden Wendungen aber ist gemeinsam, daß sie eine Geschichte, ein

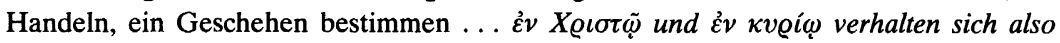
wesentlich wie Indikativ zu Imperativ « (148f.); vgl. auch G. Friedrich, Der Brief an die Philippeı. NTD 8, Göttingen 1976, 169-171.

87 Vgl. N. Brox, Past (s. Anm. 5), 162. 51.

$88 \mathrm{Vgl}$. J A. Allen, Formula (s. Anm. 85), 118.

89 P. Trummer, Paulustradition (s. Anm. 1), 200.

90 $\mathrm{Da}$ auch 1 Tim 1 12-17 »Pls« das ihm zuteil gewordene Erbarmen als Erweis des Heilswillens Gottes versteht, belegt der Ausklang in dem Lobpreis Gottes in v. 17.

91 Vgl. R. Bultmann, Theologie des Neuen Testaments, 7. erw. Aufl, hrsg. v. O. Merk, UTB 630, Tübingen 1977, 488. 533 f.; N. Brox Past (s. Anm. 5), 50. 
statischen Grundlage einer Theologie bleibender Gegenwart des

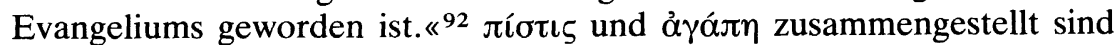
dann als die christliches Leben prägenden und bestimmenden Eigen-

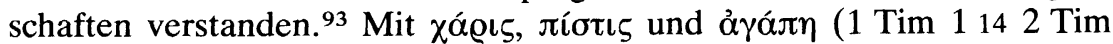
$18-14)$ ist die Gesamtheit christlicher Existenz umschrieben. Wie aber

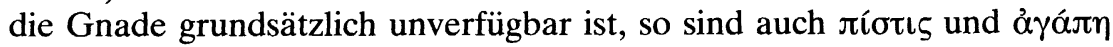
nur möglich und zu begründen »in « $u$ nd »durch « Christus Jesus. ${ }^{94}$

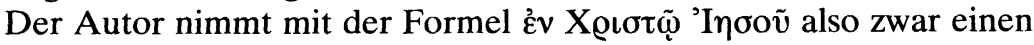
pln Sprachgebrauch auf; er orientiert jedoch diese Formel eindeutig neu $^{95}$ an seiner Christologie, die geprägt ist von der Aussage der in Jesus Christus erfolgten Offenbarung des Heilswillens Gottes, der sich als wirkmächtig nur erweisen kann in dem auf den Apostel gegründeten Glauben.

Die erwähnte These einer soteriologischen Ausrichtung der Formel

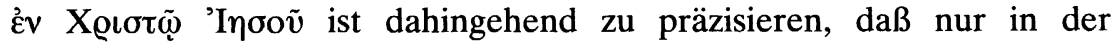
Vergangenheit und Gegenwart als Einheit fassenden Sicht »in Christus Jesus « Heil wirklich werden kann. Der Hauptakzent auch bei unserer Formel liegt wiederum in der Gegenwart; sie ist die Heilszeit.

\section{Zusammenfassung}

1. Die Christologie der Past ist v.a. geprägt durch die gegenüber der Tradition, besonders auch Pls, neuen Elemente, näherhin den Begriff

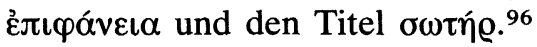

Man kann, bei aller notwendigen Zurückhaltung gegenüber einer systematisierenden Vereinheitlichung, im Bezug auf die Past von einer »Epiphaniechristologie « sprechen ${ }^{97}$, jedoch unter Berücksichtigung der

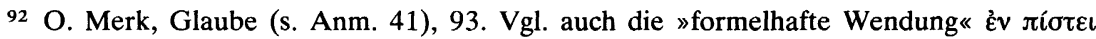
1 Tim 12427 Tit 1133 15. Dazu auch A. Lindemann, Paulus (s. Anm. 13), 143.

93 Vgl. M. Dibelius-H. Conzelmann, Past (s. Anm. 22), 23.

94 Vgl. P. Trummer, Paulustradition (s. Anm. 1), 200, der zurecht darauf verweist, daß ع̉v »keine Beschränkung auf einen lokalen oder instrumentalen Gebrauch (erlaubt)« (ebd., Anm., 184).

$95 \mathrm{Daß}$ die Formel »fast ausschließlich in der typisch Paulinischen Verwendung « begegne (F. Neugebauer, In Christus [s. Anm. 86], 175, Anm. 1; ähnlich P. Trummer, Paulustradition [s. Anm. 1], 200 mit Anm. 185), kann man nur behaupten, wenn man die eindeutige Prägung durch den Kontext ignoriert.

$96 \mathrm{Daß}$ die Christologie der Past »vor allem eine Titelchristologie « sei (P. Trummer, Paulustradition [s. Anm. 1], 193), wird man kaum behaupten können; vgl. auch N. Brox, Past (s. Anm. 5), 161.

97 Vgl. E. Pax, EПIФANEIA (s. Anm. 36), 246. Anders N. Brox, der als »beherrschend" in den »Christusaussagen der Pastoralbriefe « die »Erhöhungs-Christologie« ansieht, die dann »in den Epiphaniesprüchen (1 Tim 6142 Tim 110418 Tit 213) zur Epiphanie-Christologie` (wird)« (Past [s. Anm. 5], 165). 


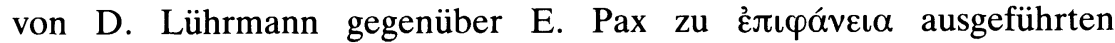
Präzisierung, daß grundsätzlich auch für das NT die im Hellenismus ausgeprägte Bedeutung als religiöser Terminus - »das geschichtlich faßbare Eingreifen Gottes zugunsten seiner Verehrer, als Ermöglichung des Sieges in einer militärischen Auseinandersetzung, aber auch allgemeiner verstanden als igöttliche Hilfe« - anzusetzen ist, die Besonderheit aber erst durch den Kontext gegeben ist. ${ }^{98}$

Die ausschließliche Bindung des Ev an die Person des Pls, wodurch das Ev selbst nicht mehr hinterfragbar ist ${ }^{99}$, und die Verpflichtung der kirchlichen Gemeindeleiter auf die Bewahrung und Weitergabe der ihnen anvertrauten $\pi \alpha \varrho \alpha \theta \dot{\eta} \kappa \eta(1 \operatorname{Tim} 6202$ Tim 1 12.14) geben auch der Christologie der Past ein stark statisches Gepräge (vgl. bes. auch die

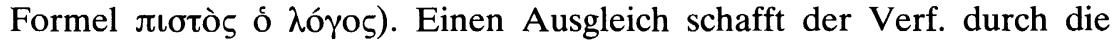

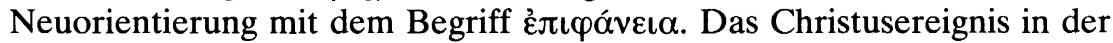
Spannung von Vergangenheit und Zukunft qualifiziert die Gegenwart als Heilszeit. In diesen dynamischen Charakter der Epiphaniechristologie fügt sich konsequent der Titel $\sigma \omega \tau \eta \mathfrak{\varrho}$ für Jesus Christus ein.

2. Die Christologie wird schon durch diese Terminologie eingebunden in die Theologie. Es ist Gottes rettendes Handeln, das in Jesus Christus sich anzeigt; Gottes Heilsratschluß ist in ihm »erschienen «. Das Christusereignis wird dadurch als soteriologisches Zentraldatum einerseits relativiert, andrerseits durch die nachdrückliche Einbindung in die »in Christus Jesus vor ewigen Zeiten « geschenkte xá ııs Gottes (2 Tim $19 \mathrm{ff}$.) und die ebenfalls von Gott zu wirkende $\dot{\pi} \pi \iota \varphi \alpha ́ v \varepsilon \iota \alpha$ »unseres Herrn Jesus Christus « (vgl. 1 Tim $614 \mathrm{ff}$.) als unverzichtbares und entscheidendes Heilsereignis eben dieses göttlichen Heilsratschlusses bestätigt und damit präzisiert (vgl. auch Tit $11-3 \quad 34-7){ }^{100}$

98 D. Lührmann, Epiphaneia (s. Anm. 36), 195f. 199. Die von H. Windisch gegen eine Epiphaniechristologie in den Past vorgebrachten Bedenken (Christologie [s. Anm. 29],

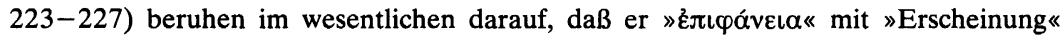
identifiziert.

99 Vgl. J. Wanke, Paulus (s. Anm. 21), 186.

100 V. Hasler betont v.a. die Zurücknahme der »soteriologischen Elemente in eine umfassende Theologie «, der Christologie in die Soter-Theologie (Epiphanie [s. Anm. 20], 195); für die Christologie bedeute dies, »daß sie ihre soteriologische Selbständigkeit verliert und lediglich eine funktionale Rolle in einem Heilssystem erfüllt, das ganz dem Epiphanieschema verpflichtet ist und die Transzendenz Gottes bewahrt« (197); die soteriologische Bedeutung des Todes Jesu bestehe »lediglich darin, daß er den ewigen Heilsbeschluß Gottes, allen Menschen das ewige Leben in Aussicht zu stellen, offenbart hat « (207).

Wenn U. Luz zu den Past feststellt, „daß die Soteriologie in ihnen die Mitte sei, wird man mit bestem Willen nicht behaupten können « (Rechtfertigung [s. Anm. 17], 377), so scheint hier doch bei aller Berechtigung einer gewissen Zurückhaltung eine zu weit gehende Ignorierung der eindeutig soteriologisch bestimmten Grundstruktur der Past mitzuschwingen. Vgl. dazu auch W. Metzger, Christushymnus (s. Anm. 8), 47. 78. 
3. Die christologische Konzeption hat man sicher auch zu sehen auf dem Hintergrund der Gefährdung des Glaubens durch Irrlehren. Bei aller durch die Dürftigkeit der inhaltlichen Bezugnahme seitens des Autors bedingten Problematik einer genaueren Bestimmung der theologischen Positionen dieser Irrlehrer kann man eine antignostische Tendenz nicht in Abrede stellen (1 Tim 620; vgl. 1 Tim 242 Tim 225 37 Tit 1 1). ${ }^{101}$ Zur Gesamttendenz der Past, die Soteriologie in der Gotteslehre zu begründen und sie damit inhaltlich an die feste Lehre der Kirche zu binden, würde es zudem passen, würde man das Schwergewicht der Irrlehre in einer »enthusiastischen Christologie « sehen (vgl. 2 Tim 2 18); ${ }^{102}$ antidoketistische Tendenzen dürfen auch an anderen Stellen vermutet werden (vgl. 1 Tim 25316613 ; auch 2 Tim $28) .{ }^{103}$

4. Die spezifische Leistung des Autors der Past und damit deren bleibende Bedeutung liegt in der Betonung der unverzichtbaren Bindung der Soteriologie an die Theologie. In dieser - in situationsbedingt anderer Weise auch für das Wirken Jesu und seine Verkündigung charakteristischen - Hinordnung auf den Heilswillen Gottes und seine Erfüllung könnte die bleibende Aktualität der Christologie dieser ntl Spätschriften gerade auch für die heutige christologische Diskussion liegen.

101 »Die Häretiker sind Gnostiker, die neben typisch gnostischen auch judaistische Züge aufweisen ...« (K. Wegenast, Verständnis [s. Anm. 21], 138. 136-138). Zu den Irrlehren vgl. auch M. Dibelius-H. Conzelmann, Past (s. Anm. 22), 52-54; G. Haufe, Gnostische Irrlehre und ihre Abwehr in den Pastoralbriefen, in: K.-W. Tröger (Hrsg.), Gnosis und Neues Testament, Berlin 1973, 325-339, bes. 325-333; N. Brox, Past (s. Anm. 5), 31-39; U. B. Müller, Zur frühchristlichen Theologiegeschichte. Judenchristentum und Paulinismus in Kleinasien an der Wende vom ersten zum zweiten Jahrhundert n. Chr., Gütersloh 1976, 53-77; P. Trummer, Paulustradition (s. Anm. 1), 161-172; W. Metzger, Christushymnus (s. Anm. 8), 30-40.

102 Vgl. G. Haufe, Irrlehre (s. Anm. 101), 328. 330. Mit Verweis auf die Parallelität zu Pol 2 Phil 71 auch J. A. Fischer, Die Apostolischen Väter, München 1956, 259, Anm. 90; A. Lindemann, Paulus, (s. Anm. 13), 230.

103 Vgl. W. Metzger, Christushymnus (s. Anm. 8), 126. 132. Dagegen spricht nicht, daß sich diese antidoketistische Spitze nur auf Andeutungen beschränkt; denn der Verf. der Past will sich nicht inhaltlich mit den Irrlehren auseinandersetzen, sondern nur die (Gegen-)Position des orthodoxen Glaubens bestarken. Es ist immerhin auffällig, daß in der ausdrücklichen antidoketistischen Polemik bei Ignatius der Hinweis auf Jesu wirk-

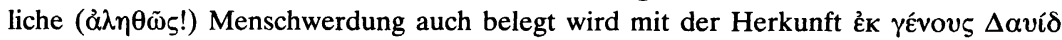

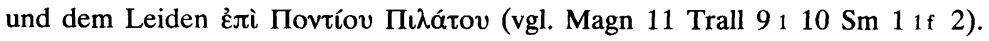

